\title{
El protocolo modificatorio al T-MEC. Su recepción en derecho interno
}

\section{Manuel Becerra Ramírez*}

El 30 de noviembre de 2018 se firmó el Tratado México, Estados Unidos, Canadá (T-MEC, o USMCA por sus siglas en inglés — United States-Mexico-Canada Agreement- -), nombre que fue propuesto por el expresidente de Estados Unidos, Donald Trump. El tratado que sustituye al Tratado de Libre Comercio de América del Norte (TLCAN). El T-MEC presenta características que sin duda son interesantes para el estudio de los tratados internacionales. También es notable la adopción de un protocolo de modificaciones a éste, que se gesta en la discusión en el seno del Poder Legislativo estadounidense, y al que nos referiremos en este comentario, haciendo hincapié en su recepción en la legislación mexicana.

En forma inusual a la práctica común de negociación de un tratado, después de que el T-MEC fue firmado por los tres países, y cuando fue sometido a su aprobación en el Congreso estadounidense, surgió la presión de los legisladores del Partido Demócrata para modificarlo. Por lo cual, de facto, se abrió su discusión, cuando ya estaba el proceso muy adelantado: negociado, firmado y enviado a los órganos de control legislativo interno correspondientes. Aunque en realidad no se abrió a la negociación, pues los cambios propuestos por el Poder Legislativo estadounidense fueron aceptados sin cambios por Canadá y México, aunque sí tuvieron que ser pasados por el órgano legislativo interno para su aprobación.

Esta necesidad de cambios dentro del Legislativo estadounidense no fue nueva. Recordemos que en el caso del TLCAN se firmaron lo que se llama-

* Universidad Nacional Autónoma de México, México; ORCID ID: https: / /orcid.org/00000003-3957-9446,manuelbramirez5@hotmail.com. 
ron cartas paralelas, ${ }^{1}$ que en la práctica eran modificaciones a dicho tratado, aunque con una dudosa legalidad, ya que esas cartas paralelas no fueron firmadas por los autorizados en el derecho de los tratados, ni siquiera pasaron por los órganos legislativos de México. Además, hay que decirlo, ante la afirmación de que estas cartas paralelas puedan ser consideradas como parte del derecho consuetudinario, esta es una práctica que solo se conoce en Estados Unidos, por lo que no crea costumbre internacional.

Ahora bien, derivado del proceso de aprobación del T-MEC, dentro del Congreso estadounidense surgió una modificación antes de entrar en vigor, ya que no se había ratificado por los tres Estados parte. Por tanto, tenemos dos fenómenos: 1) la modificación de un tratado que todavía no entraba en vigor, y 2) que se realiza una modificación sin que sea resultado de una negociación, como normalmente sucede con los tratados internacionales. ${ }^{2}$

El asunto trascendente para nuestro tema es que el protocolo realiza modificaciones a varias partes del Tratado, en lo que se refiere a las normas de propiedad intelectual (PI), y en forma más concreta, a los farmacéuticos. Los temas que se modificaron fueron varios, aquí nos interesa detenernos en uno que seguro podría causar un problema de carácter binacional.

En materia de patentes, de acuerdo con el protocolo, se suprime el párrafo que se refería a las patentes de nuevo uso, ${ }^{3}$ que es lo que se conoce también como "reverdecimiento". Con esto ya no se permiten las patentes de segundos usos.

Ahora bien, el reconocimiento de las patentes de segundo uso es bastante polémico, pues de alguna manera significa una prolongación del plazo de la

1 Cruz Miramontes, Rodolfo, "El Tratado de Libre Comercio de América del Norte y las denominadas «cartas paralelas»", Anuario Mexicano de Derecho Internacional, México, vol. 1, pp. 12-164.

2 En realidad, el protocolo no fue una propuesta ni de Canadá ni de México, fueron exigencias del representante de comercio y algunos miembros del Congreso de los EE UU. "The U.S. Trade Representative (USTR) and some Members of Congress negotiated proposed changes to the USMCA to address ongoing congressional concerns. USTR then negotiated the amendments with USMCA parties". "USMCA: Amendment and Key Changes", Congressional Research Service, 2020, disponible en: https: / / crsreports.congress. gov/product/pdf/IF/IF11391.

3 El párrafo suprimido del artículo 20:36 es: “Sujeto a los párrafos 3 y 4 y de conformidad con el párrafo 1, cada Parte confirma que las patentes están disponibles para invenciones que se reivindiquen como al menos uno de los siguientes: nuevos usos de un producto conocido, nuevos métodos de usar un producto conocido, o nuevos procedimientos de uso de un producto conocido". 
vigencia del monopolio patentario, pues es volver a contar el plazo de vigencia de las patentes, indebidamente, pues no se puede decir que una patente es nueva cuando ya se otorgó para una invención farmacéutica y de pronto se descubre que tiene un uso diferente al original.

Técnicamente se puede decir que este tipo de patentes no son nuevas, pues carecen de novedad, no tiene un mérito inventivo; lo nuevo es, quizá, el descubrimiento de otro resultado en el organismo, no el producto. ${ }^{4}$

Ciertamente, quienes promueven este tipo de patentes secundarias son las grandes empresas trasnacionales de origen estadounidenses, pues ni México ni Canadá abogaron por que se incluyeran, sin embargo, fueron removidas del T-MEC, precisamente por el poderoso cabildeo que realizó el partido Demócrata en el Legislativo estadounidense. En efecto, ni los negociadores canadienses ni los estadounidenses querían las patentes de segundo uso, fundamentalmente por el impacto que se produce al acceso de la población a los fármacos, aparte de que viola el derecho humano a la salud, es impopular para todo gobierno los precios tan altos de los medicamentos de patente.

Por eso, llama la atención el caso de México que al adoptar su Ley Federal de Protección a la Propiedad Industrial (LFPPI) el 1 de julio de 2020, haya incluido en su legislación las patentes de segundo uso, incluso en violación del Protocolo Modificatorio del T-MEC.

Artículo 45. Para los efectos del presente Capítulo se entenderá por:

I. Nuevo, todo aquello que no se encuentre en el estado de la técnica. No se excluirá de la patentabilidad a cualquier sustancia, compuesto o composición comprendida en el estado de la técnica, siempre y cuando su utilización sea nueva (el énfasis añadido es mío).

Esta postura del legislador mexicano, a todas luces violatoria del Protocolo Modificatorio del T-MEC, también es violatoria de la Constitución, que en su artículo 1o. contiene un bloque constitucional de derechos humanos, en el que se encuentra el derecho a la salud.

4 Minutti Pérez, Karla, "Patentes de segundo uso en el Acuerdo Transpacífico de Cooperación Económica”, en Pérez Miranda, Rafael y Becerra Ramírez, Manuel (coords.), En la frontera de la propiedad intelectual, México, UAM Azcapotzalco, 2019, pp. 301-308. 